\title{
The ultrastructure of cardiac myxoma
}

\author{
W. JONES WILLIAMS, D. JENKINS, and D. ERASMUS \\ Departments of Pathology and Zoology, Welsh National School of Medicine and \\ University Coilege, Cardiff
}

\begin{abstract}
A detailed study has been made of the ultrastructure of a cardiac myxoma from a man aged 41 years. It consists of abundant mucoid stroma in which are scattered single or grouped rounded or stellate cells. The stroma consists mainly of finely granular material with scanty fibrin which is seen predominantly on the surface aspect. No formed collagen is found. The myxoma cells contain numerous mitochondria, Golgi complexes and associated vesicles, moderate amounts of rough endoplasmic reticulum and scanty residual bodies. There is little evidence of pinocytosis. They also contain similar granular material to that found in the stroma. We consider, therefore, that the myxoma cells are biosynthetically active and are responsible for the production of the stroma. Morphologically the lesion does not show the features of a thrombus and we consider that it is most probably a neoplasm, although at present there is no evidence as to the cell of origin.
\end{abstract}

Cardiac myxoma is a rare lesion of uncertain nature and disputed origin. It occurs as a gelatinous mass, usually in the left atrium. It presents with signs of valvular stenosis, usually mitral stenosis, multiple emboli, and many bizarre generalized symptoms associated with high levels of $\gamma$ globulins (Heath, 1968).

The nature of cardiac myxoma has long been controversial and it has been considered to be either an atypical organizing thrombus (Thorel, 1915) or a connective tissue neoplasm (Ribbert, 1910). Recent reports, based on light microscopy and histochemistry, favour the idea that it is a neoplasm (van den Berg and Blok, 1966 ; Heath, 1968). Matsuyama and Ooneda (1967), Stein, Mauro, Thibodeau, and Alley (1969) and Merkow, Kooros, Magovern, Hayeslip, Weikers, Pardo, and Fisher (1969) described the fine structure and, though their evidence is inconclusive, also considered the lesion to be neoplastic.

We present a study of the ultrastructure of one case of atrial myxoma.

\section{CLINICAL FEATURES}

A previously fit 41-year-old man suddenly developed transient, left-sided hemiplegia, later followed by intermittent claudication in both legs, in association with an ESR of $70 \mathrm{~mm}$./hour and raised $\alpha$ and $\gamma$ globulins. Six months after the initial episode he developed congestive cardiac failure with signs of mitral stenosis and persistently raised globulins. Exploration of the mitral valve showed no abnor- mality but the left atrium was filled with a soft. friable, mucoid mass, attached by a pedicle to the posterior aspect of the anterior commissure of the mitral valve. Post-operatively the patient developed a left hemiparesis which persisted for six months, but he has now been fit and well for two years.

HISTOLOGY The myxoma consists of abundant, amorphous, mucoid tissue with scattered single and grouped rounded or stellate cells. Thin-walled capillaries are present, particularly at the site of the pedicle. The superficial portions of the myxoma show deposited fibrin. The matrix stains for both acidic and neutral mucoproteins, as demonstrated by staining respectively with alcian blue and the periodicacid Schiff reaction. Sections stained with van Gieson's stain show scanty collagen. A few reticulin fibres are also present, as shown by Gordon and Sweet's technique.

\section{MATERIAL AND METHODS}

One-millimetre cubes of tissue, from the centre of the mass, were fixed in $3 \%$ glutaraldehyde for 4 hours, washed in $0 \cdot 1 \mathrm{M}$ phosphate buffer $(\mathrm{pH} 7 \cdot 4)$ for 18 hours and post-fixed in Millonig's phosphate buffered osmium tetroxide for 1 hour. All fixation was carried out at $4^{\circ} \mathrm{C}$. The blocks were then dehydrated with alcohol and embedded in araldite. Thin sections were stained with uranyl acetate and lead citrate. The sections for electron microscopy included matrix and single and clumped cells and were identified by a study of sections, $0.5 \mu$ thick, stained with toluidine blue. 


\section{RESULTS}

The predominant cell (Fig. 1), $10 \mu$ in diameter, is of uniform structure and appears rounded or pear-shaped with irregular edges, a few fingerlike large processes and some invaginations. The cells occur usually singly or in tight clusters, consisting of two to four cells. Giant cells are absent. The cells are surrounded by masses of granular matrix and occasional fibrils.

The nuclei are oval and are frequently irregular in outline. They show peripheral concentrations of chromatin. Nucleoli and mitotic figures are absent.

The cytoplasm shows the following features (Fig. 2). Numerous Golgi complexes with many small associated vesicles are seen. A moderate amount of lamellar rough endoplasmic reticulum is present together with free ribosomes, mitochondria and glycogen granules. Many cells show a few dense bodies $(0.3$ to $0.5 \mu)$ and, rarely, complex residual bodies. Occasional cells show isolated fat droplets. Fine intracytoplasmic fibrils are frequent (Fig. 2), and some are condensed to

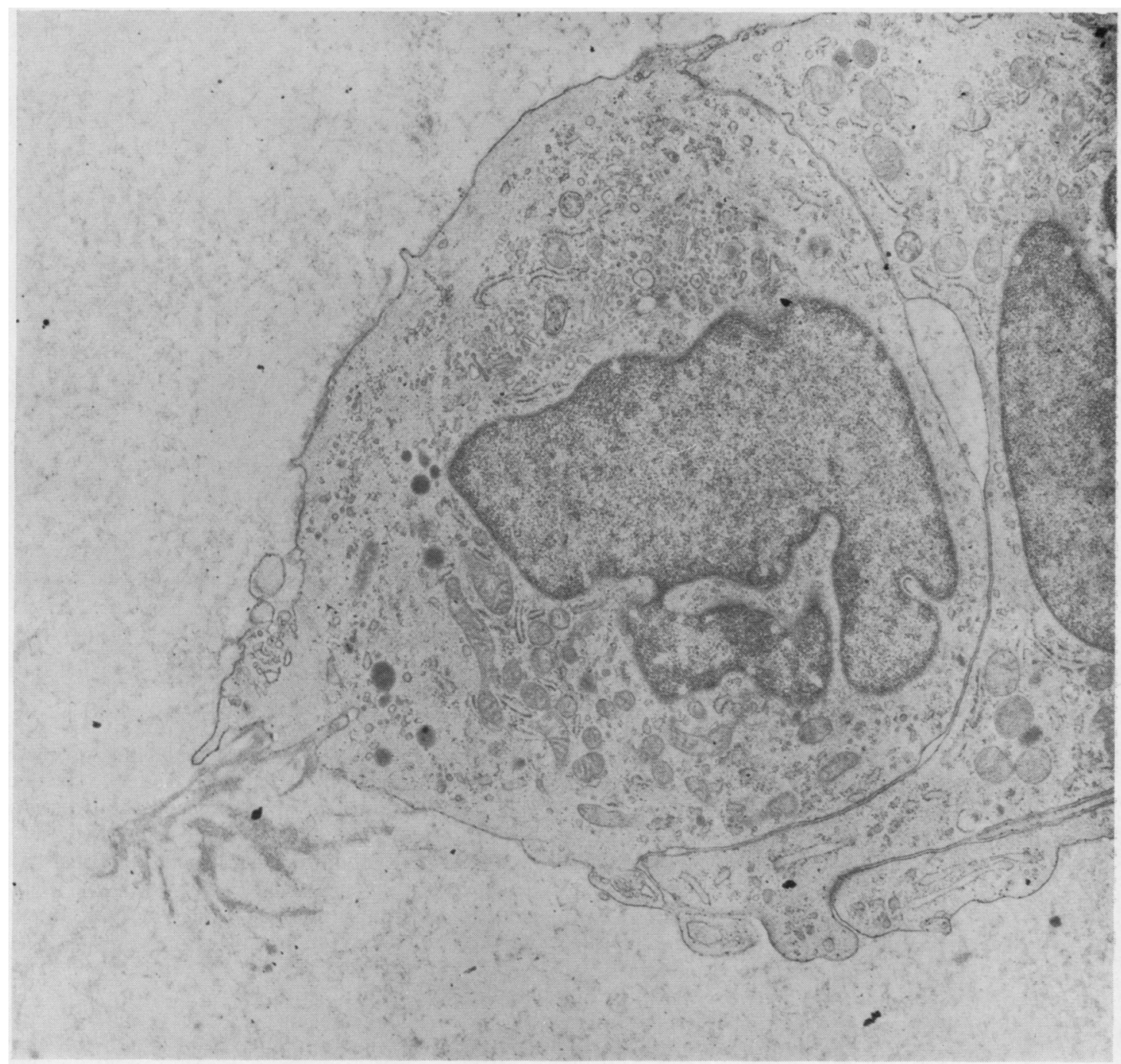

FIG. 1. Myxoma cell showing irregular nucleus, surface irregularities with lacunae and processes and a moderate number of organelles. Close apposition to adjacent cell but no tight junctions. $\times 8,350$. 


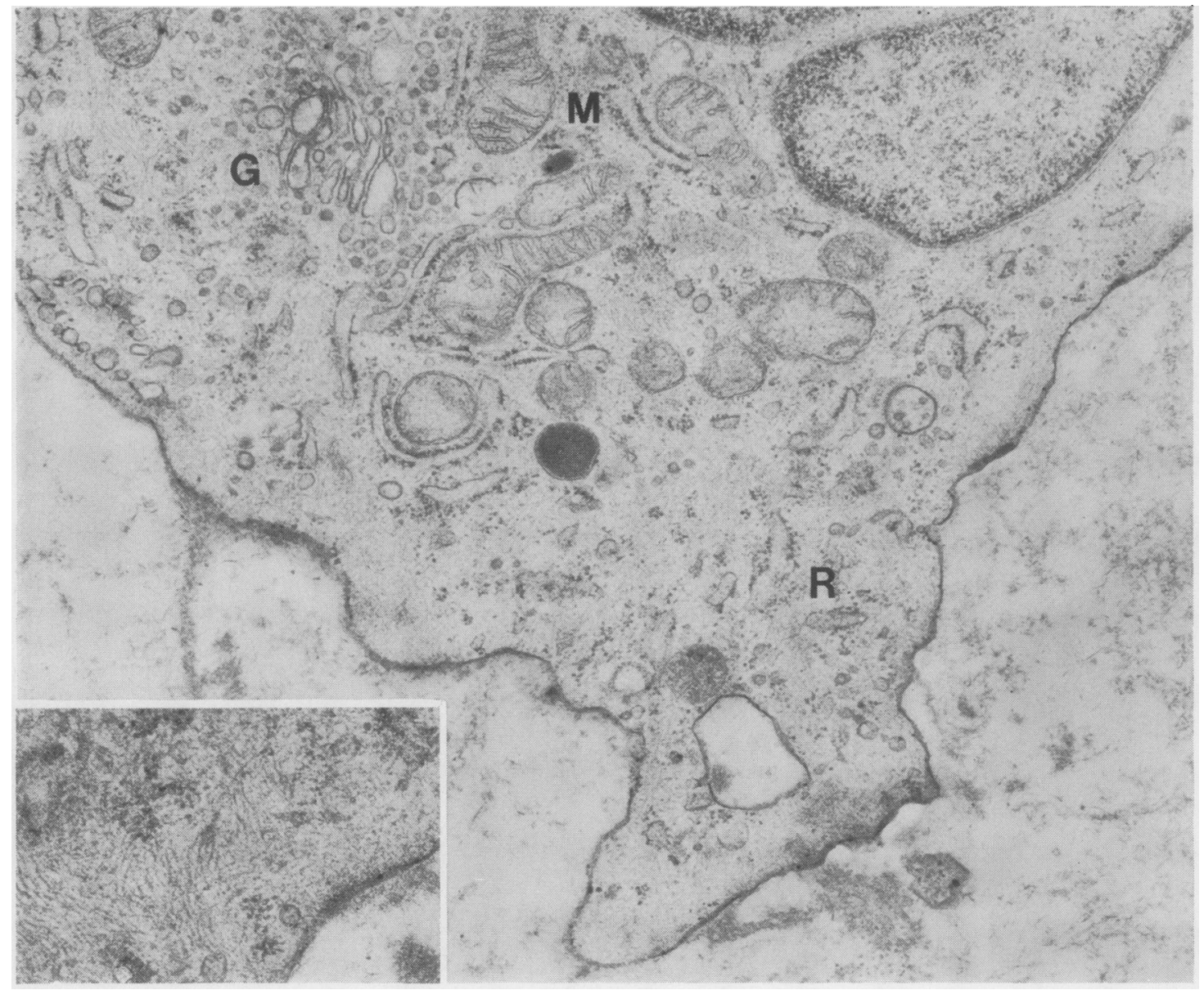

FIG. 2. Myxoma cell showing mitochondria $(M)$, rough endoplasmic reticulum $(R)$, and Golgi $(G) . \times 20,300$. Insert: Intracytoplasmic fibrils. $\times 40,600$.

form thicker fibres towards the cell edges but with no evidence of fibrillary banding. Centrioles are absent. In a few areas dense fine granular material is found associated with the inner surface of the plasma membrane.

The numerous Golgi complexes and vesicles $(500 \AA$ in diameter) contain finely granular, electron dense material. Similar vesicles and contents are also widely scattered throughout the cytoplasm. Some of the vesicles, particularly at the site of the lacunae, are in contact with, and appeared to be fused to, the plasma membrane and thus may be in continuity with the extracellular matrix (Fig. 3).

The intracytoplasmic fibrils ( $80 \AA$ in diameter) are diffusely distributed throughout the cyto- plasm. They do not show any definite relationship to the plasma membrane but tend to be condensed around cell organelles and the nucleus. They are of uniform appearance without banding or beading.

The rough endoplasmic reticulum consists of parallel cisternae, about $0 \cdot 1 \mu$ wide, with lightly stained granular contents and is widely distributed throughout the cytoplasm.

The mitochondria show well-preserved cristae and no unusual features.

The plasma membrane at the free surface of the cell is irregular and, in addition to the larger processes, shows fine $(0.1 \mu$ in diameter), elongated processes and lacunae $(0.5 \mu)$. The apposing cell surfaces are regular but there are no demon- 


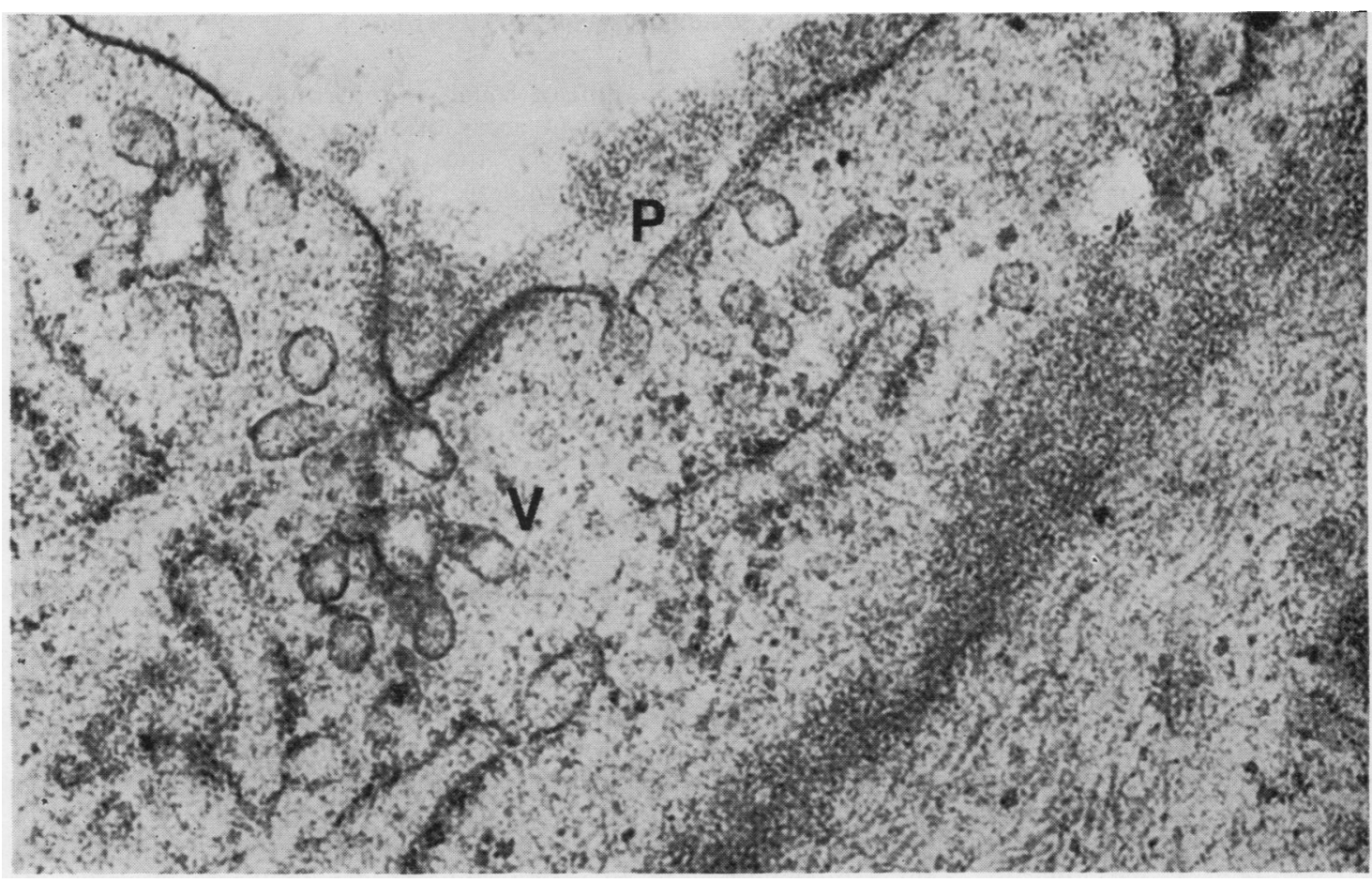

FIG. 3. Fusion of intracytoplasmic vesicles $(V)$ with plasma membrane $(P) . \times 32,000$.

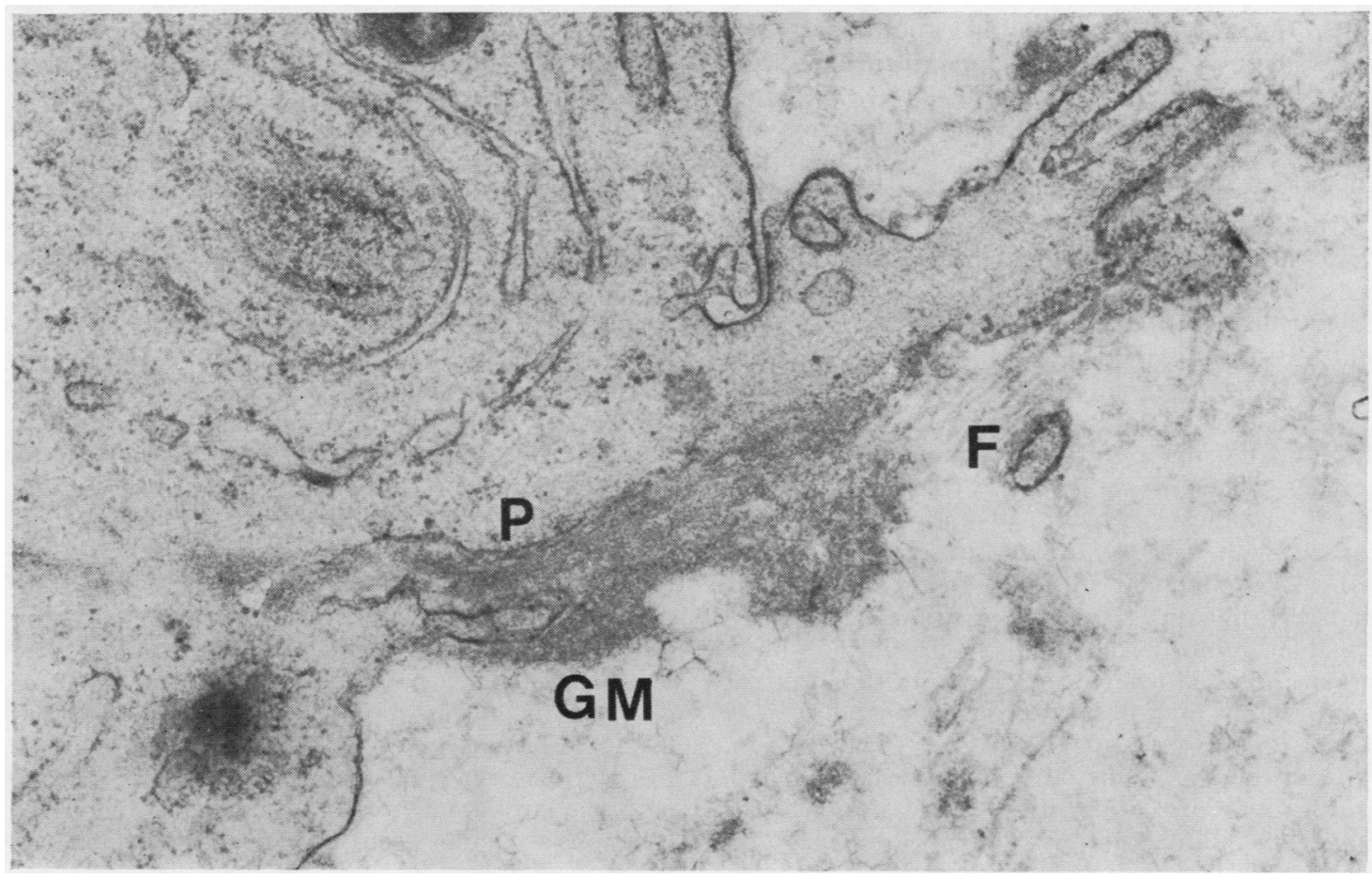

FIG. 4. Matrix consisting of finely granular material (GM), often condensed at the plasma membrane $(P)$ and showing occasional fibrils $(F) . \times 39,400$. 
strable tight junctions or desmosomes. In some areas there appear to be small intercellular spaces containing matrix but no blood cells.

The extracellular matrix (Fig. 4) consists predominantly of loose, finely granular material with areas exhibiting a fibrillary pattern. The fibrillary areas contain fibrils of two sizes, $100 \AA$ and $500 \AA$ in diameter. The latter occasionally showed suggestions of fibrin type beading $(250 \AA)$ but no collagen banding. In some areas the granular matrix is condensed at the plasma membrane and appears to be in continuity with similar material in the cell cytoplasm and vacuoles.

\section{DISCUSS:ON}

The nature and origin of cardiac myxoma can be decided only by a close study of the nature and interrelationship of the two major components, matrix and cells. Our material was unsuitable for histochemistry at ultrastructural level so we are dependent on pure morphology.

On light microscopy and histochemistry the matrix consists of amorphous material rich in mucoproteins, particularly acid mucopolysaccharides (Heath, 1968). We have shown that the major part consists of finely granular material with included fine fibrils. Some fibrils show fibrin type banding but, contrary to previous reports (Matsuyama and Oeneda, 1967), none showed collagen banding. It is, therefore, possible that some part of the matrix may be derived from plasma though the overall appearances are very different from normal thrombus.

Our evidence, though not conclusive, suggests that the matrix is derived from the myxoma cells. This view is supported by the following observations: $(a)$ the continuity of similar intraand extra-cellular granular material, particularly at the site of lacunae; $(b)$ the close proximity of Golgi vesicles to plasma membrane ; and (c) the finding of similar granular material in Golgi vesicles. The myxoma cells contain numerous Golgi complexes which are known to be concerned with the production of complexed proteins. We conclude that the major part of the matrix originates from the myxoma cells with a possible minor contribution from the blood stream. The latter feature may be expected as, from light microscope observations, fibrin is found on the free surfaces.

The myxoma cells are characterized by the uniformity of organelles. The presence of numerous mitochondria, Golgi complexes and associated vesicles, together with a moderate amount of rough endoplasmic reticulum, suggests that they are metabolically and biosynthetically active. They thus show features consistent with matrix synthesis. It is unlikely that myxoma cells are responsible for the production of the excess or abnormal circulating globulins (Goodwin, 1963), as globulin-producing cells, e.g., plasma cells, usually show much more prominent lamellar rough endoplasmic reticulum.

Though our material was unsuitable for the identification of lysosomes and residual bodies by specific staining for acid phosphatase, 'dense' and 'complexed' bodies in individual cells were sparse. We think, therefore, that it is unlikely that the small vesicles at the site of lacunae and plasma membrane are pinocytotic vesicles, as suggested by Merkow et al. (1969), but are more likely to be secretory vesicles.

Another interesting feature of the myxoma cells are the numerous contained fibrils. It is, however, difficult to characterize a particular cell from the type or amount of intracytoplasmic fibrils. Such fibrils and microtubules are common in a large variety of cells and are thought to be mainly concerned with the maintenance of overall cell form (Porter and Pappas, 1959). Fibroblasts (Ross, 1968) and endothelial cells (Nakao and Angrist, 1967) show many, but not diagnostic fibrils. Muscle cell fibrils may be specifically stained and frequently show local nodularity and 'knot' formation (Ishikawa, 1968). Our material was unsuited for specific staining and no fibrils showed nodularity. Fine intracytoplasmic fibrils are also common in embryonic cells (Buckley and Porter, 1967), but we have to conclude that the fibrils are not indicative of any particular cell of origin.

It is apparent that on pure morphology the exact identity and origin of myxoma cells is not possible. We found no evidence to support the contention that the myxoma cells are modified muscle cells (Merkow et al., 1969 ; Ribbert, 1910). In the absence of associated collagen we do not consider that the myxoma cells are fibroblasts. Though we suggest that the myxoma cells secrete the mucoprotein-rich matrix, this does not help in identifying the cell of origin as so many different cells are capable of synthesizing these substances. The presence of numerous intracytoplasmic fibrils favours an endothelial cell origin (Fine, Morales, and Horn, 1968), but as intracytoplasmic lipid droplets were rare, definite evidence of pinocytosis was absent and tight junctions were not seen, we consider the evidence to be inconclusive. 
In conclusion, we consider that the ultrastructure of cardiac myxoma cells is not indicative of the cell of origin, although the cells described are probably the source of the mucoid stroma. It is likely that the lesion is a tumour.

We are indebted to Mr. D. M. E. Thomas and Dr. R. M. E. Seal, Sully Hospital, Cardiff, for the clinical information and for access to material.

\section{REFERENCES}

Buckley, I. K., and Porter, K. R. (1967). Cytoplasmic fibrils in living cultured cells. Protoplasma (Wien), 64, 349.

Fine, G., Morales, A., and Horn, R. C. (1968). Cardiac myxoma. Cancer (Philad.), 22, 1156.

Goodwin, J. F. (1963). Diagnosis of left atrial myxoma, Lancet, $1,464$.

Heath, D. (1968). Pathology of cardiac tumors. Amer. J. Cardiol., 21, 315 .
Ishikawa, H. (1968). In situ demonstration of heavy meromyosinbound filaments in sectioned preparations. J. Cell Biol., 39, 65A.

Matsuyama, K., and Ooneda, G. (1967). Histogenesis of primary myxoma of the heart. Gann, 58, 435.

Merkow, L. P., Kooros, M. A., Magovern, G., Hayeslip, D. W., Weikers, N. J., Pardo, M., and Fisher, D. L. (1969). Ultrastructure of a cardiac myxoma. Arch. Path., 88, 390.

Nakao, K., and Angrist, A. A. (1967). The electron microscopy of nonbacterial valvular vegetations in rats with arteriovenous shunts. Brit. J. exp. Path., 48, 294.

Porter, K. R., and Pappas, G. D. (1959). Collagen formation by fibroblasts of the chick embryo dermis. J. biophys. biochem. Cytol., 5, 153.

Ribbert, H. (1910). Uber das Myxom. Frankfurt. Z. Path., 4, 30.

Ross, R. (1968). The fibroblast and wound repair. Biol. Rev., 43, 51.

Stein, A. A., Mauro, J., Thibodeau, L., and Alley, R. (1969). The histogenesis of cardiac myxomas. In Pathology Annual, ed. S. C. Sommers, vol. 4, p. 293. Butterworths, London.

Thorel, C. (1915). Geschwülste des Herzens. Ergebn. allg. Path. path. Anat., 17 (2), 677.

van den Berg, C., and Blok, A. P. R. (1966). Myxoma cordis. Some morphological and enzyme-histochemical aspects. Path. europ., 1,3 . 